\title{
An Optimal Allocation of losses and size in Power System Network with Dispersed Generation
}

\author{
Satyanarayana Addala, I.E.S. Naidu
}

\begin{abstract}
In the Power System the distribution of the loss allocation to clients is a difficult issue for the effective power. They are various s loss allocations methods have been utilized to set up suitable economic punishments or prizes. The real power and operating cost are additionally influenced with dissemination organizes loss allocation, and in this way power advertises requires appropriate methodology for reasonable portion of loss allocations among network members. This paper presents three different techniques for obtained losses allocations distribution network with dispersed generation. Within the sight of dispersed generation, the different power streams in distributed network for embracing works to recognize among the commitments that increase or decrease the losses. The proposed three methods are tested in 16 \& 69 Node Radial distribution network and its outcomes are contrasted and those of different strategies.

Keywords: Dispersed Generation (DG), Radial distribution network (RDN), Branch Current Decomposition (BCD), Power summation algorithm (PSA).
\end{abstract}

\section{INTRODUCTION}

In the expansions of utilization of dispersed generation and the exchange of allocated loads from client mode to just for summers have changed distributed network from latent to dynamic mode. Therefore, a portion of the distributed systems issues have been across the board to allocated loads too. The principle issues are loss allocation and Size, which indicates the segment of all out allotment losses at each load, is responsible. Most of the strategies actualized for circulation distribution loss allocation was principally proposed that transmission loss allocation as Pro-rata, which dispenses the dissemination losses to DG's and loads dependent on their dynamic influence levels.

Peripheral strategy, which conclude the negligible loss coefficients dependent on the result of power stream; these coefficients are utilized to discover the loads in absolute losses; the outcomes of this techniques requires resolution so as to reward for over-recuperation of influence power loss. Direct loss coefficients technique open is utilized to locate an instant connection between the losses and nodal infusions. Both these strategy depend upon effects of Newton Raphson

Revised Manuscript Received on December 13, 2019.

* Correspondence Author

Mr.Satyanarayana Addala *,Department of Electrical \& Electronics Engineering, Gitam University, Visakhapatnam, India. Email:addalasatyam@gmail.com

Dr.I.E.S. Naidu, Department of Electrical \& Electronics Engineering,Gitam University, Visakhapatnam, India. Email:iesnaidu@gmail.com control stream. Thus, the issues of intensity in real power are a precise distribution network.

Correspondingly in the substitution technique also, the obligation of a member is processed by subtracting the all out losses; this strategy is demonstrated to give out of line outcomes. Circuit-based strategy additionally include a collection of techniques as pursues Z-bus technique where it isn't to appropriation losses containing just overhead lines.

Brief strategy is additionally considered in active and reactive power streams for loss assignment and is corrected. It is to be notable of giving trustworthy results under demanding conditions.

Branch current decomposition method (BCDM), is also one of the best method for allocating of power losses to each node. The losses are registered dependent on the current $\mathrm{a}$ in its branches.

The proposed part of allocation of power loss strategy is executed on an simple allocation system, whose chart is exposed below

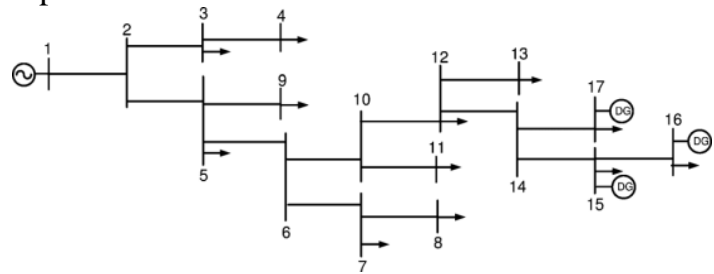

Fig. 1. 16-bus diagrams with DGs

The dispersed generations are treated as pessimistic loads for real power stream computations. The projected strategy can likewise be applied to a bigger framework containing 69 nodes.

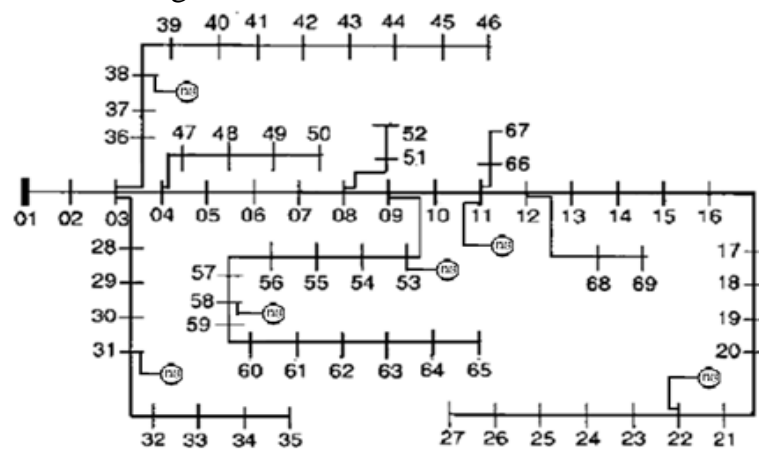

Fig.2. 69-bus diagram with DGs

The outcomes of projected techniques depend on the user location and demand. In the figure, it is shown that loss allocated at eight nodes is very high. 


\section{An Optimal Allocation of losses and size in Power System Network with Dispersed Generation}

The trivial technique used to compute the Jacobin matrix, an extra computation desirable for this power loss allocation technique. Similarly, the $\mathrm{Z}$ bus technique is framed. In similarity, the proposed method doesn't require any additional computation except for the outcomes of power stream. The techniques, for example $\mathrm{Z}$ bus in the beginning derived for power loss allocation. In view of the fact that the power losses designated to slack bus ought to be nil, the outcomes of such techniques needs tweaked, so as to bargain out losses apportioned to slack bus among other nodes. In qualification, the projected strategy was from the start for conveyance arrange, it doesn't need such adjustment.

\section{OVERVIEW OF LOSS ALLOCATED TECHNIQUES}

In the recent trends, Different allocation of loss techniques has been figure the impact of various members on the complete total system losses. In a liberalize marketplace, the information can be used to stay away from cross subsidize in the transmission and distribution fees of consumers, to create incentives of the participant and to change the consumption in periods with overcrowding or to estimate the value of distributed generation in an particular area. The allocation of the system losses has been analyzed and the aim of the analyses is twofold. Firstly, they are supposed to provide an overview of the losses in the power system.

\section{The following questions should be considered:}

1. How large are the total losses compared to the load and production?

2. Where in the system are the losses dissipated?

3. What are the losses caused by the integration of DG and the transfer of reactive power?

4. What are the potential savings in losses if the simultaneity between load and production is increased?

The most available loss allotments strategies that can be commonly generalized as pro-rata, z-bus techniques. The vital numerical equation of every one of these methodologies, just as creators' projected technique, is illustrated as pursues.

\section{A.Pro-rata allocation}

The pro-rata allocation technique is a finest power allocation loss technique. It shows losses based on a assessment of power utilized by exact load to the total power delivered by the system [3]. Initial a solved load flow solutions, power losses is steadily dispersed based on real power utilized at nodes.

$$
\begin{aligned}
& L_{G i}=\frac{P_{\text {loss }}}{x} \frac{P_{G i}}{P_{G}} \\
& L_{D j}=\frac{P_{\text {loss }}}{x} \frac{P_{D j}}{P_{D}}
\end{aligned}
$$

The above equations represent a pro-rata allocation of power losses to generator at bus $\mathrm{i}$ and $\mathrm{j}$. where $\mathrm{x}$ is a multiplying factor, which is used as weight of the distribution system.

The projected technique is completely dependent on power injected at buses and independent of network topology. Power losses are circulated around all buses based on level of utilization. The two loads in dissimilar locations other than the same weights will distributed the same level of losses, irrespective of their relative nearness to system production. Therefore, this technique will promote a damaging type rivalry.

Moreover, no inducement is make available for inserting generation nearer to consignee centers, which tends to reduction in losses. The pro-rata technique is not capable to trace power flows, making it complicated to give good reason for the different allocations.

Allocation of losses by means of loss formula represents a broad range of unlike accomplishments of complete and exact computation and allocation of power losses. Different execution including the Z-bus technique, B loss coefficients and quadratic function transactions are happening in the power network.

\section{B.Z Bus Loss Allocation technique}

The $\mathrm{Z}$ bus allocation of power loss technique is based on total system losses, which is an easy approach that tells directly to the equations to calculate load flow condition [3]. Therefore, the Total losses can be expressed as

$\mathrm{P}_{\text {loss }}=\operatorname{Real}\left\{\sum_{\mathrm{k}=1}^{\mathrm{n}} \mathrm{V}_{\mathrm{k}} \mathrm{I}_{\mathrm{k}}{ }^{*}\right\}$

$P_{\text {loss }}=\operatorname{Real}\left\{\sum_{k=1}^{n} I_{k}{ }^{*}\left(\sum_{j=1}^{n} Z_{k j} I_{j}\right)\right\}$

The above equations can modified as written as

$P_{\text {loss }}=$

$\operatorname{Real}\left\{\sum_{k=1}^{n} I_{k}^{*}\left(\sum_{j=1}^{n} R_{k j} I_{j}\right)\right\}+$

$\operatorname{Real}\left\{\sum_{k=1}^{n} I_{k}{ }^{*}\left(\sum_{j=1}^{n} J X_{k j} I_{J}\right)\right\}$

(5)

$P_{\text {loss }}=\operatorname{Real}\left\{\sum_{k=1}^{n} I_{k}{ }^{*}\left(\sum_{j=1}^{n} R_{k j} I_{j}\right)\right\}$

Therefore the total losses can be written as

$L_{k}=\operatorname{Real}\left\{I_{k}{ }^{*}\left(\sum_{j=1}^{n} R_{k j} I_{j}\right)\right\}$

$\mathrm{P}_{\text {loss }}=\sum_{\mathrm{k}=1}^{\mathrm{n}} \mathrm{L}_{\mathrm{k}}$

\section{C.Branch Current Decomposition Method [2]}

Considering a distribution network, in which the root node is implicit as slack.

The current flowing through branch $\mathrm{b}$

$\bar{I}^{(b)}=\alpha^{(b)}+j \beta^{(b)}$

and the output current from node $\mathrm{k}$

$\bar{I}_{k}=\alpha_{k}+j \beta_{k}$

the branch losses as expressed as

$$
\begin{aligned}
L^{(b)} & =R^{(b)}\left(I^{(b)}\right)^{2}=R^{(b)}\left[\left(\alpha^{(b)}\right)^{2}+\left(\beta^{(b)}\right)^{2}\right] \\
& =\left(R^{(b)} \alpha^{(b)}\right) \alpha^{(b)}+\left(R^{(b)} \beta^{(b)}\right) \beta^{(b)}
\end{aligned}
$$

Where $R^{(b)}$ is resistance of the branch

The above equation can re rewritten as

$L^{(b)}=R^{(b)} \alpha^{(b)} \sum_{k \in K^{(b)}} \alpha_{k}+R^{(b)} \beta^{(b)} \sum_{k \in K^{(b)}} \beta_{k}$

The losses linked to branch $\mathrm{b}$ as follows

$L_{k}{ }^{(b)}=R^{(b)} \alpha^{(b)} \alpha_{k}+R^{(b)} \beta^{(b)} \beta_{k}$ fork $\epsilon K^{(b)}$

The entire losses are given by using the relationship

$$
\begin{aligned}
L_{k}=\sum_{b=1}^{B} L_{k}^{(b)} & =\alpha_{k} \sum_{b \in B_{k}}\left(R^{(b)} \alpha^{(b)}\right) \\
& +\beta_{k} \sum_{b \in B_{k}}\left(R^{(b)} \beta^{(b)}\right)
\end{aligned}
$$

$=c_{k} \alpha_{k}+d_{k} \beta_{k}$

$\bar{w}_{k}=c_{k}+j d_{k}$ at node $\mathrm{k}$, such that

$L_{k}=\operatorname{Re}\left(\bar{w}_{k} \bar{I}_{k}^{*}\right)$ 
In this paper, we are introducing a new method called PSMLA technique for allocation of power loss allocation in distribution power network using dispersed generation.

\section{THE PROPOSED METHOD (PSMLA)}

A simple diagram, distribution network with dispersed generation is shown in Fig.3.[1]

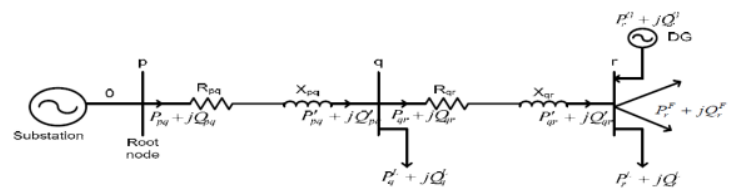

Fig. 3. A Simple DN with DGS

From this Fig.3., it is to be considered that feeders from substation to root node is assumed as lossless. The above distribution network is customized by varying the sink of the generator at node $\mathrm{P}$.

Therefore,

Generator output at node $\mathrm{P}=$ Total demand + total network losses

The total complex power at any node is given by:

$P_{i}+j Q_{i}=P_{i(\text { Load })}-P_{i(D G)}+j\left(Q_{i(\text { Load })} \pm\right.$

$Q_{i(D G)}-\frac{1}{2} \sum_{j \in \gamma} B_{j} \cdot U_{i}^{2}(15)$

If DG generates reactive power, it gives negative sign and positive sign when it consumes. A power loss in any branch is given by:

$\Delta P_{m}+j Q_{m}=Z_{m} \cdot I_{m}^{2}=\frac{\left(R_{m}+j X_{m}\right)}{U_{m}^{2}} \cdot\left(P_{m(\text { end })}^{2}+Q_{m(\text { end })}^{2}\right)$

The Active and Reactive power losses can be expressed as

$\Delta P_{m}+j \Delta Q_{m}=\sum_{i \in \alpha} \Delta P_{m}^{i}+j \sum_{i \in \alpha} \Delta Q_{m}^{i}$

$\Delta P=\sum_{m=1}^{n} \Delta P_{m}=\sum_{m=1}^{n} \sum_{i \in \alpha} \Delta P_{m}^{i}$

The total active losses at node $i$

$\Delta P^{i}=\sum_{m=1}^{n} \Delta P_{m}^{i}$ or $\Delta P^{i}=\sum_{m \in \gamma} \Delta P_{m}^{i}$

Total losses are given by

$\Delta P=\sum_{i=1}^{n} \Delta P^{i}$

Emphasize that all out losses allocated with PSMLA are equivalent to add up to total losses in the system determined with influence stream.

\section{RESULT}

\section{BUS SYSTEM - SOURCE}

\begin{tabular}{|c|c|c|c|}
\hline & BCDLA & Z BUS & PSMLA \\
\hline REAL POWER KW & 1483.2 & 1483.2 & 875.2 \\
\hline $\begin{array}{c}\text { REACTIVE POWER } \\
\text { KVAR }\end{array}$ & 1112.4 & 1112.4 & 656.4 \\
\hline $\begin{array}{c}\text { REAL POWER } \\
\text { LOSS KW }\end{array}$ & 0.0269 & 0.0269 & 0.0081 \\
\hline $\begin{array}{c}\text { REACTIVE POWER } \\
\text { LOSS KVAR }\end{array}$ & 0.0278 & 0.0278 & 0.0084 \\
\hline TOTAL COST I RS & 113.1442 & 113.1442 & 42.627 \\
\hline
\end{tabular}

16 BUS SYSTEM - SINK

\begin{tabular}{|c|c|c|c|}
\hline & BCDLA & Z BUS & PSMLA \\
\hline REAL POWER KW & 1483.2 & 1483.2 & 1483.2 \\
\hline $\begin{array}{c}\text { REACTIVE POWER } \\
\text { KVAR }\end{array}$ & 1112.4 & 1112.4 & 1112.4 \\
\hline $\begin{array}{c}\text { REAL POWER LOSS } \\
\text { KW }\end{array}$ & 0.0269 & 0.0269 & 0.0269 \\
\hline $\begin{array}{c}\text { REACTIVE POWER } \\
\text { LOSS KVAR }\end{array}$ & 0.0278 & 0.0278 & 0.0278 \\
\hline
\end{tabular}

\begin{tabular}{|c|c|c|c|}
\hline TOTAL COST I RS & 113.14 & 113.14 & 141.43 \\
\hline
\end{tabular}

\begin{tabular}{|c|c|c|}
\hline \multirow{2}{*}{} & \multicolumn{2}{|c|}{ PSMLA } \\
\cline { 2 - 3 } & $\begin{array}{c}\text { WITHOUT } \\
\text { DG }\end{array}$ & WITH DG \\
\hline REAL POWER KW & 819.8720 & 1311.7952 \\
\hline $\begin{array}{c}\text { REACTIVE POWER } \\
\text { KVAR }\end{array}$ & 614.9040 & 983.8464 \\
\hline $\begin{array}{c}\text { REAL POWER LOSS } \\
\text { KW }\end{array}$ & 8.2413 & 21.1662 \\
\hline $\begin{array}{c}\text { REACTIVE POWER } \\
\text { LOSS KVAR }\end{array}$ & 7.4857 & 19.2511 \\
\hline TOTAL COST I RS & 34653.00 & 88999.79 \\
\hline
\end{tabular}

69 BUS SYSTEM - SOURCE

\begin{tabular}{|c|c|c|}
\hline & \multicolumn{2}{|c|}{ PSMLA } \\
\cline { 2 - 3 } & $\begin{array}{c}\text { WITHOUT } \\
\text { DG }\end{array}$ & WITH DG \\
\hline REAL POWER KW & 819.8720 & 1330.9952 \\
\hline $\begin{array}{c}\text { REACTIVE POWER } \\
\text { KVAR }\end{array}$ & 614.9040 & 998.2464 \\
\hline $\begin{array}{c}\text { REAL POWER LOSS } \\
\text { KW }\end{array}$ & 8.2413 & 21.4750 \\
\hline $\begin{array}{c}\text { REACTIVE POWER } \\
\text { LOSS KVAR }\end{array}$ & 7.4857 & 19.4896 \\
\hline TOTAL COST I RS & 34653 & 90297.98 \\
\hline
\end{tabular}

PSMLA -DG \& SIZE ALLOCATION -SINK \& SOURCE

\begin{tabular}{|c|c|c|c|c|c|c|}
\hline NODE & 11 & 22 & 31 & 38 & 53 & 58 \\
\hline SIZE & 0.72 & 0.144 & 0.288 & 1.44 & 0.332 & 0.576 \\
\hline
\end{tabular}

\section{v. Conclusion}

In this paper, they are three distinct strategies for allotment of power losses and DG size in distributed networkwith dispersed generations been analyzed and the outcomes are displayed. All these three methods are having their unique pros and cons. The results for the three methods are tested for 16 bus system and 69 bus systems. By testing the results of all these methods it is observed that PSM for Loss Allocation is perfectly capable and appropriate techniques for solving problems in distributed network. This method exactly allocates the total losses without any need for settlement. The pros of the proposed PSM is easily understandable and the execution of the technique is simple and don't require a complex programming. All the results are tested in MATLAB software.

\section{REFERENCES}

1. M Atanasovski and R Taleski, "Power summation method for loss allocation in radial distribution networks with DG," IEEE Trans. Power Syst., vol. 26, no. 4, pp. 2491-2499, Nov. 2011.

2. E Carpaneto,GChiccoandJ S Akilimali, "Branch current decomposition method for loss allocation in radial distribution systems with distributed generation," IEEE Trans. Power Syst., vol. 21, no. 3, pp. 1170-1179, Aug. 2006.

3. A JConejo,FDGaliana and I Kochar,"Z-bus loss allocation," IEEE Trans. Power Syst., vol. 16, no. 1, pp. 105-110, Feb. 2001.

4. J Mahil,SatyanarayanaAddala, AntoSpirituskingly, "Hybrid search algorithm for security constrained unit commitment solution" ,ijeat,2019.

5. JMutale,GStrbac,S Curcic, and N Jenkins, "Allocation of losses in distribution systems with embedded generation," in Proc. Inst. Elect. Eng., Gen., Transm. Distrib., Jan. 2000, vol. 147, no. 1, pp. 7-14. 


\section{An Optimal Allocation of losses and size in Power System Network with Dispersed Generation}

\section{AUTHORS PROFILE}

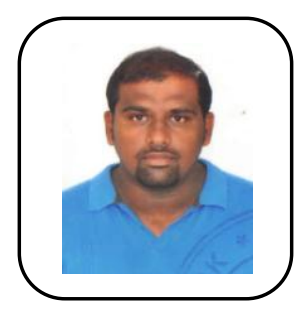

Mr.SatyanarayanaAddalareceived his B.Tech. degree in Electrical \& Electronics engineering in 2007 and M.Tech degree in Powers system \& Automation in 2010. Currently, he is pursuing $\mathrm{PhD}$ degree in Electrical \& Electronics engineering at "GITAM Deemed to be University", Visakhapatnam. His research interests are Distributed generation, smart Grids,Renewable Energy Systems.

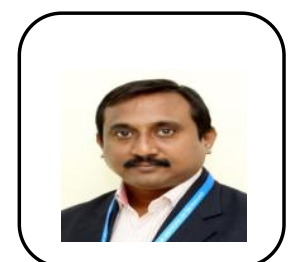

Dr.I.E.S.Naidu received his BTech in Electrical and Electronics Engineering from JNTU, Hyderabad and MTech in Advanced Power Systems from the JNTU, Kakinada in2001 and 2005 respectively. He was awarded Doctorate in Electrical Engineering by Andhra University in 2018. During 2005-2006, he worked with ANITS College and presently he is working as Associate Professor in the Electrical \& Electronics Engineering Department, GITAM Visakhapatnam campus, India. His research interests include power system stability and power system security. 